Llop, S., Casas, L., Santa Marina, L., Estarlich, M., Fernández-Somoano, A., Esplugues, A., Jimenez, A., Zock, J.P., Tardón, A., Marco, A., Ballester, F. Prenatal and postnatal residential usage of insecticides in a multicenter birth cohort in Spain. Science of the Total Environment: 7 2013, 445-446, 273-280

\begin{tabular}{|l|l|}
$\begin{array}{l}\text { Postprint } \\
\text { Version }\end{array}$ & 1.0 \\
\hline Journal website & http://www.sciencedirect.com/science/article/pii/S0048969712015811 \\
\hline Pubmed link & $\underline{\text { http://www.ncbi.nlm.nih.gov/pubmed/23337604 }}$ \\
\hline DOI & $10.1016 /$ j.scitotenv.2012.12.031
\end{tabular}

This is a NIVEL certified Post Print, more info at http://www.nivel.eu

\title{
Prenatal and postnatal residential usage of insecticides in a multicenter birth cohort in Spain
}

\author{
SABRINA LLOP ${ }^{\mathrm{A}, \mathrm{B},}$ LIDIA CASAS $^{\mathrm{C}, \mathrm{D}, \mathrm{B}}$, LORETO SANTA MARINA ${ }^{\mathrm{B}, \mathrm{E}, \mathrm{F}}$, MARISA ESTARLICH $^{\mathrm{A}, \mathrm{B}}$, \\ ANA FERNÁNDEZ-SOMOANO ${ }^{\mathrm{B}, \mathrm{G}}$, ANA ESPLUGUES ${ }^{\mathrm{A}, \mathrm{B}, \mathrm{G}}$, ANA JIMENEZ ${ }^{\mathrm{E}}$, JAN-PAUL ZOCK ${ }^{\mathrm{C}, \mathrm{D}, \mathrm{B}}$, \\ ADONINA TARDÓN $^{\mathrm{B}, \mathrm{H}}$, ALFREDO MARCO ${ }^{\mathrm{B}, \mathrm{I}}$, FERRAN BALLESTER ${ }^{\mathrm{A}, \mathrm{B}, \mathrm{G}}$ \\ ${ }^{a}$ Centre for Public Health Research (CSISP), Av. Catalunya 21, 46020 Valencia, Spain \\ ${ }^{\mathrm{b}}$ CIBER de Epidemiología y Salud Pública (CIBERESP), Melchor Fernández Almagro 3-5, \\ 28029 Madrid, Spain \\ ${ }^{c}$ Centre for Research in Environmental Epidemiology (CREAL), Doctor Aiguader 88, 08003 \\ Barcelona, Spain \\ d IMIM (Hospital del Mar Research Institute), Doctor Aiguader 88, 08003 Barcelona, Spain \\ e Departamento de Sanidad Gobierno Vasco, Subdirección de Salud Pública de Gipuzkoa, \\ Avenida de Navarra 4, 20013 San Sebastián, Spain \\ ${ }^{\dagger}$ Biodonostia, Instituto de Investigación Biomédica, Doctor Begiristain, s/n, 20014 San \\ Sebastián, Spain \\ ${ }^{9}$ Faculty of Nursing, University of Valencia, Jaume Roig s/n, 46010, Valencia, Spain \\ ${ }^{\mathrm{h}}$ Area de Medicina Preventiva y Salud Pública, Universidad de Oviedo, Campus El Cristo \\ s/n 33006, Oviedo, Spain \\ ' Hospital Universitario La Fe, Bulevar Sur s/n, 46026, Valencia, Spain
}

\begin{abstract}
This study aimed to describe the residential use of insecticides in a birth cohort in Spain. Study subjects were 2456 women enrolled into the INMA (Environment and Childhood) birth cohort followed prospectively during pregnancy and in the early postnatal period. The women were recruited at the beginning of their pregnancy between 2003 and 2008 in four regions of Spain. Socio-demographic, environmental and lifestyle information was obtained at two interviews during pregnancy, one at the first (mean:13.8 \pm 2.6 weeks of gestation) and the other at the third trimester (mean: $33.3 \pm 2.3$ weeks of gestation). Information about prenatal use of indoor and outdoor insecticides (type, timing, place of application, place of storage) was obtained from the second interview. In a 3rd interview (mean: $16.2 \pm 6.9$ months of age of children), information about postnatal indoor and outdoor insecticide use was obtained. Regression models examined the association between demographic and lifestyle factors and pesticide use to determine which characteristics predicted use prenatally and postnatally. Fifty-four percent of women reported using indoor insecticides during pregnancy, $45 \%$ in their bedroom and $47 \%$
\end{abstract}


Llop, S., Casas, L., Santa Marina, L., Estarlich, M., Fernández-Somoano, A., Esplugues, A., Jimenez, A., Zock, J.P., Tardón, A., Marco, A., Ballester, F. Prenatal and postnatal residential usage of insecticides in a multicenter birth cohort in Spain. Science of the Total Environment: 7 2013, 445-446, 273-280

elsewhere in the house. Plug-in devices were the most frequent application methods used in the pregnant woman's bedroom and insecticide sprays elsewhere in the house. The maternal factors related to prenatal use of indoor insecticides were parity, country of birth, educational level, region of residence, having a garden or yard with plants, and living near an agricultural area. These products continued to be used postnatally, although $20 \%$ of the women stopped using them. Foetuses and children are especially vulnerable to pesticide exposure; thus knowing how pesticides are used during pregnancy and infancy may be a starting point for the study of their potential effects on health as well as useful for designing preventive actions.

\section{Highlights}

- Foetuses and children are especially vulnerable to residential insecticide exposure. - We described the use of residential insecticides in a birth cohort in Spain. $54 \%$ of women reported using insecticides at home during pregnancy. Maternal associated factors were: parity, country of birth and educational level. The habit of using pesticides continued postnatally.

\section{BACKGROUND}

Pesticides are widely used both indoors and outdoors to control pests. Insecticides are specifically to control insect pests. Insect repellents are products that people use on their skin, clothing, or in their immediate surroundings to repel or keep away annoying insects (EPA, 2009). Studies conducted in the United States of America (USA) showed that a high percentage (80-95\%) of the population used some type of pest control measures at home (Davis et al., 1992, Adgate et al., 2000 and Whyatt et al., 2002), and the most frequently used were spray insecticides (Wu et al., 2011). According to the results of the ALSPAC study (Avon Longitudinal Study of Parents and Children) in Bristol (UK), 93\% of parents used one or more indoor or outdoor pesticide products. Insecticides in the home were the most commonly applied pesticides (Grey et al., 2006). Berkowitz et al. (2003) showed that $46 \%$ of pregnant women belonging to a multiethnic cohort from New York stated that they or another household member had applied pesticides inside the home, although they did not find an association between pesticide questionnaire data and urinary metabolites $(3,5,6-$ trichloro-2-pyridinol, phenoxybenzoic acid, and pentachlorophenol).

The main routes of exposure to residential pesticides are inhalation, dermal contact, and non-intentional ingestion (Driver et al., 2005). Exposure through inhalation depends on certain factors such as how long pesticides persist indoors, the volatility of the active ingredient or ventilation of the dwelling. Dermal exposure may occur when the pesticide is applied or when residents come into contact with contaminated surfaces. In addition, this primary exposure route may differ based on the age of the subject. In toddlers and children the ingestion of contaminated house dust represents the most important route of exposure to residential pesticides (USEPA, 1990). Infants spend more time indoors and generally wear less clothing than adults; their breathing zone is closer to the floor, where pesticide residues may be highest, and they are more apt to have intimate contact with floors, turf and other residential surfaces. They have considerably higher breathing rates and engage in much more "mouthing" activities (hands, toys and furniture) than adults, which may result in ingestion of dermal residues, dust, and soil (National Research Council, 1993, Xue et 
Llop, S., Casas, L., Santa Marina, L., Estarlich, M., Fernández-Somoano, A., Esplugues, A., Jimenez, A., Zock, J.P., Tardón, A., Marco, A., Ballester, F. Prenatal and postnatal residential usage of insecticides in a multicenter birth cohort in Spain. Science of the Total Environment: 2013, 445-446, 273-280

al., 2007 and Xue et al., 2010). Furthermore, foetuses and children are especially vulnerable to pesticide exposure due to their immature detoxification and immune systems, compared with those of adults, and the fact that they have more time in which to develop chronic diseases that may be initiated by early exposures (Landrigan et al., 1999).

Some residential pesticides have been detected in biological samples collected during pregnancy or childhood (Adgate et al., 2001, Berkowitz et al., 2003 and Quackenboss et al., 2000), and these exposures have been adversely related to foetal growth (Whyatt et al., 2004) and neurological (Rauh et al., 2011) effects, as well as to increased incidence of childhood leukaemia (Maele-Fabry et al., 2011).

Pyrethroids are the most common active ingredient used in current residential insecticides. They are not volatile and have a short half life after being absorbed (Maroni et al., 2000). Several studies have detected urinary metabolites of pyrethroids in the general population, especially in children (Fortin et al., 2008, Naeher et al., 2010 and Barr et al., 2010). Levels of pyrethroid urinary metabolites in children have been associated with the residential use of insecticides (Becker et al., 2006 and Naeher et al., 2010). The postnatal exposure to these compounds has been mainly associated with effects on male reproduction (Koureas et al., 2012), since experimental studies have shown that they can induce a disruption in nervous system development (Cao et al., 2011).

The purpose of this study is to describe the use of indoor and outdoor insecticides prenatally and postnatally among participants in a longitudinal birth cohort study in Spain.

We examined socio-demographic and lifestyle factors predicting the use of insecticides during pregnancy and postnatally, since it would make it possible to design strategies to reduce insecticide exposure and prevent possible deleterious effects related to prenatal and early childhood exposure to insecticides. As far as we know, this is the first study conducted in Spain to describe the habit of insecticide use among pregnant women and mothers with young children.

\section{METHODS}

\subsection{Study population and study area}

This study is framed within the INfancia y Medio Ambiente (INMA) Project (Environment and Childhood), the aim of which is to study the effect of environmental exposures, diet and genetics on foetal and child development in a cohort of pregnant women and their offspring in different regions of Spain (http://www.proyectoinma.org/). The study protocol has been reported elsewhere (Ribas-Fitó et al., 2006 and Guxens et al., 2011). Briefly, 2644 pregnant women were recruited during the first trimester (10-13 weeks of gestation) of pregnancy between November 2003 and February 2008. The inclusion criteria were: (1) an age of 16 years or over; (2) 10-13 weeks of gestation; (3) singleton pregnancy; (4) intention of undergoing follow-up and delivering in the corresponding centre of reference; (5) no impediment for communication; and (6) no chronic disease prior to the pregnancy. These women were followed up during pregnancy $(n=2525,95 \%)$ until delivery (n $=2506,95 \%$ ). Their children were enrolled at birth and followed up postnatally ( $\mathrm{n}=$ $2360,89 \%)$. The final study population consisted of pregnant women $(n=2456)$ and early postnatal mothers $(n=2308)$ with complete data on all covariates. 
Llop, S., Casas, L., Santa Marina, L., Estarlich, M., Fernández-Somoano, A., Esplugues, A., Jimenez, A., Zock, J.P., Tardón, A., Marco, A., Ballester, F. Prenatal and postnatal residential usage of insecticides in a multicenter birth cohort in Spain. Science of the Total Environment: 7 2013, 445-446, 273-280

The women were recruited from 4 regions of Spain: Sabadell (Catalonia), Gipuzkoa (Basque Country), Asturias and Valencia. Each region was divided into different sub-areas based on socio-demographic and environmental characteristics. The Valencia region was divided into 3 sub-areas (\% of women living there): urban (85\%), semi-urban (12\%), and rural (3\%). The Sabadell region was exclusively urban. Ninety-two percent of the pregnant women from the Asturias region lived in the urban zone, whereas 7 and 1\% lived in semi-urban and rural zones, respectively. Finally, nearly half of women from Gipuzkoa lived in the urban zone (49\%), 38\% in the semi-urban zone and $13 \%$ in the rural zone.

Informed consent was obtained from all participants at each stage and the study was approved by the Ethics Committees of the hospitals in the participating regions.

\subsection{Data collection}

Socio-demographic, environmental and life-style information was obtained through questionnaires administered during pregnancy and at one point postnatally. These questionnaires were administered by trained interviewers in the reference hospitals or primary care centres when women attended regularly scheduled prenatal visits. The first questionnaire was administered during the first trimester of pregnancy (mean: $13.8 \pm 2.6$ weeks of gestation) when the pregnant women attended their antenatal appointment. The socio-demographic information obtained from this questionnaire was: maternal and paternal age, educational level (primary or without education, secondary, university), country of birth (Spain, other), and type of area of residence (urban, semi-urban/rural) during pregnancy.

The second questionnaire was administered during the third trimester of pregnancy (mean: $33.3 \pm 2.3$ weeks of gestation) when the pregnant women attended another antenatal appointment. From this questionnaire we obtained information about maternal and paternal smoking habit during pregnancy (yes, no), maternal and paternal employment status during pregnancy (employed, unemployed), parity (0, 1 , $\geq 2$ ), having a garden or yard at home (no, yes), and proximity to an agricultural area (no, yes). Information about prenatal use of indoor insecticides was also obtained: type of application (spray insecticide, plug-in device or others), timing (whole year, occasionally or seasonally), and place of application (pregnant woman's bedroom or elsewhere in the house), as well as information about the use of insect repellents. Finally, we obtained information about the place of storage and the timing (every month, every 2-3 months, 3 times/year or occasionally) of prenatal use of outdoor insecticides among families who had gardens with plants.

In a 3rd interview, when the children were $16.2 \pm 6.9$ (mean $\pm \mathrm{sd}$ ) months old, information about postnatal use of indoor insecticides was obtained: type of application (spray insecticide, plug in device or others), timing (whole year, occasionally or/and seasonally) and place of application (children's bedroom or elsewhere in the house), as well as information on insect repellents. We also obtained information about the place of storage and timing (every month, every 2-3 months, 3 times/year or occasionally) of postnatal use of outdoor insecticides among families who had gardens with plants. Other covariates obtained in this interview were: maternal and paternal smoking habit during the infancy (yes, no), maternal and paternal job situation during the infancy (employed, unemployed), having a garden or yard at home (no, yes), and proximity to an agricultural area (no, yes).

A scheme describing the data collected at each visit can be found in Table 1. 
Llop, S., Casas, L., Santa Marina, L., Estarlich, M., Fernández-Somoano, A., Esplugues, A., Jimenez, A., Zock, J.P., Tardón, A., Marco, A., Ballester, F. Prenatal and postnatal residential usage of insecticides in a multicenter birth cohort in Spain. Science of the Total Environment: 7 2013, 445-446, 273-280

\section{[TABLE 1]}

The use of insecticides at least once a week throughout the year was considered whole year use, less than once a week was considered occasional use and frequent use during one season each year was considered seasonal use. In all cases during the prenatal and postnatal periods we only considered the use of insecticides made by the family and not commercial applications.

We defined parental social class according to the most privileged occupation during pregnancy of the mother or the father using a widely used Spanish adaptation of the international ISCO88 coding system (Domingo-Salvany et al., 2000). Class I included managerial jobs, senior technical staff, and commercial managers; class II included skilled non-manual workers; and class III, manual workers.

\subsection{Data analysis}

A descriptive analysis was performed to describe prenatal and postnatal insecticide usage and storage habits in the women's dwellings. Spearman's correlation was obtained to examine the association between potential predictor variables.

Univariate and multivariable logistic regression models were used to determine which demographic and lifestyle factors predicted the use of residential insecticides during pregnancy (no, yes). Univariate regression models examined the association between each individual predictor and each pesticide use outcome.

We used a two-step procedure: first we run univariate regression models between the insecticide exposure variables and each covariate. From these, we selected the variables related to the insecticide use (Wald's test, $\mathrm{p}<0.1$ ) to compose the multivariable models. Then we introduced all these variables in the model and using a backward procedure we retained the variables that significantly improved the model using the likelihood ratio test $(\mathrm{p}<0.1)$. The fully adjusted model included all socio-demographic, environmental and lifestyle covariates significant in the univariate models $(\mathrm{p}<0.1)$ and in the likelihood ratio test $(\mathrm{p}<0.1)$ using a backward procedure.

To examine changing residential insecticide use during and following pregnancy, we constructed a variable using the information on prenatal and postnatal use of indoor insecticides. The objective was to identify the women who reported using insecticides prenatally, but not postnatally (yes, no); and those who reported using them only postnatally, but not prenatally (yes, no). A similar analytical approach was used for this analysis as for the predictors of prenatal and postnatal use. Univariate analyses were used to identify important predictors, followed by multivariable models to describe the greatest variance in pesticide use behaviour. We also tested for collinearity between the variables retained in the multivariable models and found none.

All statistical analyses were performed with STATA® Version 11 statistical software.

\section{RESULTS}

\subsection{A. Study population}

Characteristics of the study population are shown in Table 2. Nearly half of the women belonged to a lower social class (43\%), more than half were primiparous (57\%), 16\% did not work during pregnancy, most of them were Spanish (92\%) and lived in an urban area (81\%), and secondary education was the most frequently 
Llop, S., Casas, L., Santa Marina, L., Estarlich, M., Fernández-Somoano, A., Esplugues, A., Jimenez, A., Zock, J.P., Tardón, A., Marco, A., Ballester, F. Prenatal and postnatal residential usage of insecticides in a multicenter birth cohort in Spain. Science of the Total Environment: 7 2013, 445-446, 273-280

reported level of educational attainment among the women (41\%). Almost all fathers worked during pregnancy (99\%) and only $1 \%$ of these had a job related to the agricultural sector. During pregnancy, the percentage of men who smoked was significantly higher than that of women (39\% versus 17\%), but postnatally this difference was attenuated (39\% versus 26\%). Twenty-two percent of women had gardens or backyards with plants at home and this percentage differed according to region (42\% in Valencia, 15\% in Asturias, 27\% in Sabadell and 16\% in Gipuzkoa) and the type of area of residence (76\% in urban area and $24 \%$ in rural area). There were no significant differences between pregnant women included in the original cohort and those that were finally included in this study regarding all the covariates.

\section{[TABLE 2]}

Spearman bivariate correlation coefficients between the different covariates can be found in the supplemental material (Supplemental Table 1). We observed a weak, positive association between region of residence and presence of a garden/backyard (Spearman's $r=0.126, \mathrm{p}<0.001$ ) and residential proximity to an agricultural area (Spearman's $r=0.072, \mathrm{p}<0.001$ ). It appeared that women living in Valencia were more likely to have gardens/backyards at home and to live near to an agricultural area.

\subsection{B. Prenatal residential insecticide use}

Fifty-four percent of pregnant women used some type of insecticides indoors; $15 \%$ reported using 2 or more application methods (Table 3). Forty-five percent of pregnant women applied some type of insecticides in their bedroom $-5 \%$ throughout the year, $75 \%$ seasonally and $20 \%$ occasionally. The most frequent application method used in the bedroom was the plug-in device (62\%). Moreover, $47 \%$ of the women applied insecticides elsewhere in the home - 7\% throughout the year, $67 \%$ seasonally, and $26 \%$ occasionally. The most frequent application method used by the women elsewhere in the home was insecticide sprays (69\%). Two percent of the women used other types of pest control measures in their bedroom and five percent did so elsewhere in the house. Other pest control measures included cockroach traps, insecticide powder, and non-chemical measures such as wave devices. Only $1 \%$ of women used insect repellents during pregnancy.

\section{[TABLE 3]}

\subsection{Postnatal residential insecticide use}

Forty-five percent of the women reported using indoor residential pesticides postnatally (Table 3). Eleven percent reported using more than one application method. Thirty-three percent reported using insecticides in their children's bedroom $-4 \%$ throughout the year, $77 \%$ seasonally, and $18 \%$ occasionally. The most frequent application method in the child's bedroom was plug-in devices (75\%). Thirty-nine percent of the women reported using insecticides elsewhere in the house $-5 \%$ throughout the year, $70 \%$ seasonally, and $24 \%$ occasionally. The most frequent application method elsewhere in the house was plug-in devices (58\%). Only $0.2 \%$ of women used insect repellents at home. Eight percent of women used outdoor insecticides or other pesticides postnatally (36\% among women who had gardens or backyards at home). 
Llop, S., Casas, L., Santa Marina, L., Estarlich, M., Fernández-Somoano, A., Esplugues, A., Jimenez, A., Zock, J.P., Tardón, A., Marco, A., Ballester, F. Prenatal and postnatal residential usage of insecticides in a multicenter birth cohort in Spain. Science of the Total Environment: 2013, 445-446, 273-280

The use of insecticide sprays in the participant's bedroom has lowered from prenatal (53\%) to postnatal period (26\%) and the use of plug-in devices has increased (from $62 \%$ during pregnancy to $75 \%$ during the postnatal period). The use of insecticides and plug-in devices elsewhere in the house has remained virtually unchanged.

\subsection{Predictors of prenatal use of residential insecticides}

Supplemental Table 2 displays the socio-demographic and lifestyle characteristics potentially predictive of prenatal residential insecticide use. The strongest independent predictor of prenatal use of residential insecticides was the region of residence (pseudo $r^{2}=0.0619$ ), followed by having a garden or backyard with plants at home (pseudo $r^{2}=0.0225$ ). The region of residence was also the strongest predictor of use of insecticide sprays (pseudo $\mathrm{r}^{2}=0.0268$ ), followed by residential proximity to an agricultural area (pseudo $\mathrm{r}^{2}=0.0130$ ). Parity, country of birth and type of area of residence were positive predictors of prenatal use of indoor insecticides; however, they became negative predictors when prenatal use of insecticide sprays was studied.

Results from multivariable logistic regression models determining the sociodemographic and lifestyle predictors of prenatal insecticide use are presented in Table 4. Positive predictors include parity, Spanish origin, having a garden/yard and living near an agricultural area. Specifically, women who reported $>2$ previous pregnancies were 1.55 (95\% CI: 1.08-2.21) times more likely to use indoor insecticides than women with fewer pregnancies. The odds of indoor prenatal insecticide use was 1.78 (95\% CI: 1.31-2.41) times higher among women born in Spain than in other countries. Women who reported having a garden or backyard with plants and living near an agricultural area were 2.06 (95\% CI: 1.66-2.56) and 1.39 (95\% CI: 1.14-1.70) more likely to use indoor insecticides than women without a garden or who live far from an agricultural area, respectively. Maternal educational level was a negative predictor of using prenatal indoor insecticides; women with university studies had a lower odds of using them (OR: 0.67 (95\% CI: 0.53-0.85)) than women less educated. Geographic differences in the use of insecticides were seen: compared with those from Gipuzkoa, women from Sabadell had the highest odds (OR: 4.49 (95\% CI: 3.48-5.80)), followed by women from Valencia (OR: 3.46 (95\% CI: 2.72-4.40)) and Asturias (OR: 2.59 (95\% CI: 1.99-3.37)). The overall pseudo $r^{2}$ was 0.09 .

\section{[TABLE 4]}

We also studied the predictors of using insecticide sprays versus other methods (plug-in devices and others) prenatally. Positive predictors included social class, having a garden or backyard with plants at home and living near an agricultural area. Women who belonged to lower social class were 1.64 (95\% CI: 1.16-2.31) times more likely to use indoor insecticide sprays than higher social class women. Women who reported having a garden or backyard with plants and living near an agricultural area were 1.69 (95\% CI: $1.29-2.22)$ and 1.52 (95\% CI: $1.17-1.99)$ more likely to use indoor insecticide sprays, respectively, than women without a garden or who live far from an agricultural area. Negative predictors were parity (OR: 0.69 (95\% CI: 0.44 1.08) women who reported $\geq 2$ previous pregnancies), country of birth (OR: 0.55 (95\% CI: 0.33-0.90) Spanish women), type of area (OR: 0.54 (95\% CI: 0.36-0.81) 
Llop, S., Casas, L., Santa Marina, L., Estarlich, M., Fernández-Somoano, A., Esplugues, A., Jimenez, A., Zock, J.P., Tardón, A., Marco, A., Ballester, F. Prenatal and postnatal residential usage of insecticides in a multicenter birth cohort in Spain. Science of the Total Environment: 7 2013, 445-446, 273-280

women who lived in the urban area), and maternal educational level (OR: 0.70 (95\% CI: $0.52-0.95)$ women with secondary studies). The overall pseudo $r^{2}$ was 0.09 . We did not find any collinearity between the variables retained in the multivariable models.

\subsection{E. Change in insecticide use}

The results of univariate logistic regression models to examine associations between potential predictors and pesticide use are displayed in Supplement Table 3 stratified by women who used insecticides prenatally but not postnatally $(n=450)$ and those mothers who used insecticides postnatally but not prenatally $(n=258)$ (Table 5). Twelve percent of women reported using insecticide sprays prenatally but changed to other methods postnatally (plug-in devices or other applications). The strongest predictor of this change was the region (pseudo $r^{2}=0.020$ ), followed by the type of area (pseudo $r^{2}=0.0018$ ). Spearman's coefficient of correlation between the indoor use of residential pesticides prenatally and postnatally was $0.397(\mathrm{p}<0.001)$.

\section{[TABLE 5]}

Multivariable logistic regression coefficients are shown in Table 6. Women living in rural/semi-urban areas were more likely to stop using pesticides postnatally than women living in urban areas (OR: 1.22 (95\% CI: 0.89-1.66)), and also women who reported living near an agricultural area (OR: 1.42 (95\% CI: 0.90-2.24)). However, these variables did not reach statistical significance at the multivariable level.

\section{[TABLE 6]}

Eleven percent of the women reported using indoor insecticides postnatally, but not prenatally (Table 5). Of these, $6 \%$ reported using insecticide sprays postnatally but not prenatally since they used other methods (plug-in devices or other applications). On univariate analysis, the strongest predictor of this change was the region (pseudo $r^{2}=0.0250$ ), followed by the type of area (pseudo $r^{2}=0.0018$ ) (Supplemental Table 3 ). In the multivariable analysis we observed that non-Spanish women were 1.83 (95\% CI: 1.22-2.75) times more likely to use insecticides postnatally but not prenatally than Spanish women. Geographic differences have been found, women from Asturias were more likely to start using insecticides postnatally (OR: 2.91 (95\% CI: 1.79-4.73)) (Table 6).

\section{Discussion}

In this longitudinal birth cohort study in different regions of Spain, 54\% of the women reported using indoor insecticides prenatally - 45\% in their bedroom and $47 \%$ elsewhere in the house. Prenatal use of indoor insecticides was related to increased parity and educational level, Spanish nationality, dwellings with a garden or yard with plants, living near to an agricultural area, and living in Sabadell or Valencia. Forty-five percent of these women reported using indoor insecticides postnatally - 33\% in the child's bedroom and 39\% elsewhere in the house. Most studies on reported use of residential pesticides have been conducted among USA populations. According to the findings of these studies, some type of pesticide was used in over $80-90 \%$ of homes, both during pregnancy and during the child's infancy (Davis et al., 1992, Adgate et al., 2000, Whyatt et al., 2002, Colt et al., 2004, Williams et al., 2008 and Wu et al., 2011). These percentages are considerably 
Llop, S., Casas, L., Santa Marina, L., Estarlich, M., Fernández-Somoano, A., Esplugues, A., Jimenez, A., Zock, J.P., Tardón, A., Marco, A., Ballester, F. Prenatal and postnatal residential usage of insecticides in a multicenter birth cohort in Spain. Science of the Total Environment: 7 2013, 445-446, 273-280

higher than those found in our study, which may be due to the fact that the use of residential pesticides indoors, in the garden, and fumigations done by professionals were included.

Berkowitz et al. (2003) found that $46 \%$ of pregnant women participating in their study conducted in New York used residential pesticides. However, when they took into account fumigations by professionals indoors, this percentage rose to $70 \%$. In the Minnesota Children's Pesticide Exposure Study (MNCPES), the percentage of families with young children that used pesticides was found to be $63.7 \%$ indoors and 26.5\% outdoors (Sexton et al., 2003). These percentages are more similar to those found in our study.

There is very little bibliography describing the use of residential pesticides in countries other than the USA. In the ALSPAC (Avon Longitudinal Study of Parents and Children) cohort in Bristol (UK), 93\% of the parents reported having used residential pesticides postnatally in or around the house (Grey et al., 2006). In another study carried out in Pelotas (Brasil), 89\% of household members reported using residential insecticides indoors (Diel et al., 2003).

This study found that self-reported insecticide use increased with parity, among women born in Spain compared with those born abroad, those with a lower educational level, in dwellings with a garden or yard with plants, and in those near an agricultural area. Geographic differences were also observed; the odds of insecticide use were highest among women from the Sabadell and Valencia regions compared with women from the Gipuzkoa cohort. A possible explanation may be related to climate, as average temperatures are warmer in these two regions than in Gipuzkoa so these regions are more likely to have gardens at home and insect pests. In addition, the use of insecticide sprays was associated with a lower social class and living in an urban area. Other studies have analyzed social determinants that may be associated with residential use of pesticides during pregnancy. Berkowitz et al. (2003) reported significant differences related to maternal age, ethnicity, marital status, and maternal education in a multiethnic urban cohort of pregnant women in New York City. Pesticide use was higher among younger women, non-Caucasian women (African American, Hispanic or other), non-married women (single, separated, widowed or living with baby's father), and less educated women. Whyatt et al. (2002) observed that the quality of housing of pregnant women, as well as ethnicity, was a predictor of residential pesticide use. Adgate et al. (2000) did not find that socio-demographic factors explained variations in pesticide storage or use patterns in a sample of Minnesota households with children.

A weakness of this birth cohort study may lie in the lack of biological and environmental monitoring. However questionnaires are useful tools for assessing exposure to residential pesticides since they enable us to determine the exposure during a period of time greater than the half life of these substances. Nevertheless, our questionnaire has some limitations, i.e., the lack of information about the presence of children while the insecticide is being applied, ventilation postapplication and pet applications. Besides that the use of questionnaires does not give information on other routes of exposure such as diet, or exposure in other places such as leisure establishments or other people's homes. Finally, recall bias may lead to potential exposure misclassification. Some studies found a good correlation between the information obtained from a questionnaire on residential pesticide use patterns and the information obtained by monitoring biological samples (Colt et al., 2004 and 
Llop, S., Casas, L., Santa Marina, L., Estarlich, M., Fernández-Somoano, A., Esplugues, A., Jimenez, A., Zock, J.P., Tardón, A., Marco, A., Ballester, F. Prenatal and postnatal residential usage of insecticides in a multicenter birth cohort in Spain. Science of the Total Environment: 7 2013, 445-446, 273-280

Lu et al., 2006) while others did not (Sexton et al., 2003 and Berkowitz et al., 2003). In the INMA Project, urine samples were collected from all the participants in the cohort during pregnancy. Therefore, a study to determine pesticides or their metabolites and to provide further information on exposure may be carried out in the future.

Another strength of our study is its prospective design, thus making it possible to study the pattern of residential pesticide use at times of high vulnerability pregnancy and infancy - as well as to analyze socio-demographic and environmental factors that may determine such use. To the best of our knowledge, this is the first study to take into account a change in the use of residential pesticides occurring between pregnancy and early postnatal period, together with the determining factors.

\section{CONCLUSION}

Supplemental Table 2.

Univariate logistic regression models between use of indoor insecticides and use of insecticide sprays during pregnancy and socio-demographic and lifestyle characteristics of pregnant women. INMA Cohort, Spain, 20032008.

Help with DOC files

Options

- Download file ( K)

Supplemental Table 3.

Univariate logistic regression models between a change in habit in residential insecticide use and socio-demographic and lifestyle characteristics of pregnant women. INMA Cohort, Spain, 2003-2008 $(n=2308)$.

Help with DOC files

Options

- Download file ( K)

ACKNOWLEDGEMENTS AND FUNDING 
Llop, S., Casas, L., Santa Marina, L., Estarlich, M., Fernández-Somoano, A., Esplugues, A., Jimenez, A., Zock, J.P., Tardón, A., Marco, A., Ballester, F. Prenatal and postnatal residential usage of insecticides in a multicenter birth cohort in Spain. Science of the Total Environment: 2013, 445-446, 273-280

The authors would particularly like to thank all the participants for their generous collaboration. A full roster of the INMA Project Investigators can be found at http://www.proyectoinma.org/presentacion-inma/listado-investigadores/en_listadoinvestigadores.html. This study was funded by grants from the Instituto de Salud Carlos III (Red INMA G03/176 and CB06/02/0031); the Spanish Ministry of Health (FIS-FEDER 03/1615, 04/1509, 04/1112, 04/1931, 05/1079, 05/1052, 06/1213, 07/0314, 09/02647, 11/02591, 04/1436, 04/2018, 09/02311, 06/0867 and 08/1151); Conselleria de Sanitat Generalitat Valenciana, Generalitat de Catalunya (CIRIT 1999SGR 00241); Department of Health of the Basque Government (2005111093 and 2009111069), the Provincial Government of Gipuzkoa (DFG06/004 and DFG08/001), Obra social Cajastur, University of Oviedo, European Union Sixth Framework Project (NEWGENERIS FP6-2003-Food-3-A-016320); and Fundación Roger Torné. The study protocol was approved by the Ethics Committees of the reference hospitals (Hospital la Fe, Hospital de Sabadell, Instituto Universitario de Oncología de la Universidad de Oviedo, Hospital de Zumarraga).

\section{REFERENCES}

1. Adgate et al., 2000J.L. Adgate, A. Kukowski, C. Stroebel, P.J. Shubat, S. Morrell, J.J. Quackenboss et al.Pesticide storage and use patterns in Minnesota households with childrenJ Expo Anal Environ Epidemiol, 10 (2000), pp. 159-167

2. Adgate et al., 2001J.L. Adgate, D.B. Barr, C.A. Clayton, L.E. Eberly, N.C. Freeman, P.J. Lioy et al.Measurement of children's exposure to pesticides: analysis of urinary metabolite levels in a probability-based sampleEnviron Health Perspect, 109 (2001), pp. 583-590

3. Atmospheric Research and Exposure Assessment Laboratory, 1990Atmospheric Research and Exposure Assessment LaboratoryOffice of Research and DevelopmentUnited States Environment Protection Agency, Nonoccupational Pesticide Exposure Study (NOPES) (1990) Washington

4. Barr et al., 2010D.B. Barr, A.O. Olsson, L.Y. Wong, S. Udunka, S.E. Baker, R.D. Whitehead, M.S. Magsumbol, B.L. Williams, L.L. NeedhamUrinary concentrations of metabolites of pyrethroid insecticides in the general U.S. population: National Health and Nutrition Examination Survey 19992002Environ Health Perspect, 118 (2010), pp. 742-748

5. Berkowitz et al., 2003G.S. Berkowitz, J. Obel, E. Deych, R. Lapinski, J. Godbold, Z. Liu et al.Exposure to indoor pesticides during pregnancy in a multiethnic, urban cohortEnviron Health Perspect, 111 (2003), pp. 79-84

6. Becker et al., 2006K. Becker, M. Seiwert, J. Angerer, M. Kolossa-Gehring, H.W. Hoppe, M. Ball, C. Schulz, J. Thumulla, B. SeifertGerES IV pilot study: assessment of the exposure of German children to organophosphorus and pyrethroid pesticidesInt J Hyg Environ Health, 209 (2006), pp. 221-233|

7. Cao et al., 2011Z. Cao, T.J. Shafer, T.F. MurrayMechanisms of pyrethroid insecticide-induced stimulation of calcium influx in neocortical neuronsJ Pharmacol Exp Ther, 336 (2011), pp. 197-205

8. Colt et al., 2004J.S. Colt, J. Lubin, D. Camann, S. Davis, J. Cerhan, R.K. Severson et al.Comparison of pesticide levels in carpet dust and self-reported 
Llop, S., Casas, L., Santa Marina, L., Estarlich, M., Fernández-Somoano, A., Esplugues, A., Jimenez, A., Zock, J.P., Tardón, A., Marco, A., Ballester, F. Prenatal and postnatal residential usage of insecticides in a multicenter birth cohort in Spain. Science of the Total Environment: 7 2013, 445-446, 273-280

pest treatment practices in four US sitesJ Expo Anal Environ Epidemiol, 14 (2004), pp. 74-

9. Davis et al., 1992J.R. Davis, R.C. Brownson, R. GarciaFamily pesticide use in the home, garden, orchard, and yardArch Environ Contam Toxicol, 22 (1992), pp. 260-

10. Diel et al., 2003C. Diel, L.A. Facchini, M.M. Dall'AgnolHousehold insecticides: pattern of use according to per capita incomeRev Saude Publica, 37 (2003), pp. 83-90

11. Domingo-Salvany et al., 2000A. Domingo-Salvany, E. Regidor, J. Alonso, C. varez-DardetProposal for a social class measure. Working Group of the Spanish Society of Epidemiology and the Spanish Society of Family and Community MedicineAten Primaria, 25 (2000), pp. 350-

12. Driver et al., 2005J. Driver, J.H. Ross, M. Pandian, J. Evans, C. LunchickResidential (non-dietary) post-application exposure assessmentC.A. Franklin, J.P. Worgan (Eds.), Occupational and residential exposure assessment pesticides, John Wiley \& Sons, Ltd, England (2005), pp. 129-173

13. Environment Protection Agency (EPA), 2009Environment Protection Agency (EPA)Active ingredients found in insect repellentshttp://epa.gov/pesticides/health/mosquitoes/ai_insectrp.htm (2009)

14. Fortin et al., 2008M.C. Fortin, M. Bouchard, G. Carrier, P. DumasBiological monitoring of exposure to pyrethrins and pyrethroids in a metropolitan population of the Province of Quebec, CanadaEnviron Res, 107 (2008), pp. 343-350

15. Grey et al., 2006C.N. Grey, M.J. Nieuwenhuijsen, J. GoldingUse and storage of domestic pesticides in the UKSci Total Environ, 368 (2006), pp. 465-

16. Guxens et al., 2011M. Guxens, F. Ballester, M. Espada, M.F. Fernandez, J.O. Grimalt, J. Ibarluzea et al.Profile: the INMA - INfancia y Medio Ambiente (Environment and Childhood) projectInt J Epidemiol (2011), pp. 1-11View Record in Scopus|

17. Koureas et al., 2012M. Koureas, A. Tsakalof, A. Tsatsakis, C. HadjichristodoulouSystematic review of biomonitoring studies to determine the association between exposure to organophosphorus and pyrethroid insecticides and human health outcomesToxicol Lett, 210 (2012), pp. 155| 18.

19. Landrigan et al., 1999P.J. Landrigan, L. Claudio, S.B. Markowitz, G.S. Berkowitz, B.L. Brenner, H. Romero et al.Pesticides and inner-city children: exposures, risks, and preventionEnviron Health Perspect, 107 (Suppl. 3) (1999), pp. 431-437

20. Lu et al., 2006C. Lu, D.B. Barr, M. Pearson, S. Bartell, R. BravoA longitudinal approach to assessing urban and suburban children's exposure to pyrethroid pesticidesEnviron Health Perspect, 114 (2006), pp. 1419-

21. Maele-Fabry et al., 2011V.G. Maele-Fabry, A.C. Lantin, P. Hoet, D. LisonResidential exposure to pesticides and childhood leukaemia: a systematic review and meta-analysisEnviron Int, 37 (2011), pp. 280-291

22. Maroni et al., 2000M. Maroni, C. Colosio, A. Ferioli, A. FaitBiological monitoring of pesticide exposure: a review. IntroductionToxicology, 143 (2000), pp. 1-118 
Llop, S., Casas, L., Santa Marina, L., Estarlich, M., Fernández-Somoano, A., Esplugues, A., Jimenez, A., Zock, J.P., Tardón, A., Marco, A., Ballester, F. Prenatal and postnatal residential usage of insecticides in a multicenter birth cohort in Spain. Science of the Total Environment: 2013, 445-446, 273-280

23. Naeher et al., 2010L.P. Naeher, N.S. Tulve, P.P. Egeghy, D.B. Barr, O. Adetona, R.C. Fortmann, L.L. Needham, E. Bozeman, A. Hilliard, L.S. SheldonOrganophosphorus and pyrethroid insecticide urinary metabolite concentrations in young children living in a southeastern United States citySci Total Environ, 408 (2010), pp. 1145-1153

24. National Research Council, 1993National Research CouncilCommittee on pesticides in the diets of infants and children. Special characteristics of childrenPesticides in the diets of infants and children, National Academy Press, Washington, DC (1993), pp. 23-44

25. Quackenboss et al., 2000J.J. Quackenboss, E.D. Pellizzari, P. Shubat, R.W. Whitmore, J.L. Adgate, K.W. Thomas et al.Design strategy for assessing multi-pathway exposure for children: the Minnesota Children's Pesticide Exposure Study (MNCPES)J Expo Anal Environ Epidemiol, 10 (2000), pp. 145-158

26. Rauh et al., 2011V. Rauh, S. Arunajadai, M. Horton, F. Perera, L. Hoepner, D.B. Barr et al.Seven-year neurodevelopmental scores and prenatal exposure to chlorpyrifos, a common agricultural pesticideEnviron Health Perspect, 119 (2011), pp. 1196-1201 |

27. Ribas-Fitó et al., 2006N. Ribas-Fitó, R. Ramon, F. Ballester, J. Grimalt, A. Marco, N. Olea et al.Child health and the environment: the INMA Spanish StudyPaediatr Perinat Epidemiol, 20 (2006), pp. 403-410

28. Sexton et al., 2003K. Sexton, J.L. Adgate, L.E. Eberly, C.A. Clayton, R.W. Whitmore, E.D. Pellizzari et al.Predicting children's short-term exposure to pesticides: results of a questionnaire screening approachEnviron Health Perspect, 111 (2003), pp. 123-128

29. | Whyatt et al., 2002R.M. Whyatt, D.E. Camann, P.L. Kinney, A. Reyes, J. Ramirez, J. Dietrich et al.Residential pesticide use during pregnancy among a cohort of urban minority womenEnviron Health Perspect, 110 (2002), pp. 507-514 |

30. Whyatt et al., 2004R.M. Whyatt, V. Rauh, D.B. Barr, D.E. Camann, H.F. Andrews, R. Garfinkel et al.Prenatal insecticide exposures and birth weight and length among an urban minority cohortEnviron Health Perspect, 112 (2004), pp. 1125-1132

31. Williams et al., 2008M.K. Williams, A. Rundle, D. Holmes, M. Reyes, L.A. Hoepner, D.B. Barr et al.Changes in pest infestation levels, self-reported pesticide use, and permethrin exposure during pregnancy after the 2000-2001 U.S. Environmental Protection Agency restriction of organophosphatesEnviron Health Perspect, 116 (2008), pp. 1681-1688 |

32. Wu et al., 2011X.M. Wu, D.H. Bennett, B. Ritz, J. Frost, D. Cassady, K. Lee et al.Residential insecticide usage in northern California homes with young childrenJ Expo Sci Environ Epidemiol, 21 (2011), pp. 427-436

33. Xue et al., 2007J. Xue, V. Zartarian, J. Moya, N. Freeman, P. Beamer, K. Black et al.A meta-analysis of children's hand-to-mouth frequency data for estimating nondietary ingestion exposureRisk Anal, 27 (2007), pp. 411-420

34. Xue et al., 2010J. Xue, V. Zartarian, N. Tulve, J. Moya, N. Freeman, W. Auyeung et al.A meta-analysis of children's object-to-mouth frequency data for estimating non-dietary ingestion exposureJ Expo Sci Environ Epidemiol, 20 (2010), pp. 536-545 
Llop, S., Casas, L., Santa Marina, L., Estarlich, M., Fernández-Somoano, A., Esplugues, A., Jimenez, A., Zock, J.P., Tardón, A., Marco, A., Ballester, F. Prenatal and postnatal residential usage of insecticides in a multicenter birth cohort in Spain. Science of the Total Environment: 7 2013, 445-446, 273-280

\section{TABLES AND FIGURES}

Table 1.

Participants environmental, socio-demographic and life-style characteristics obtained in each visit.

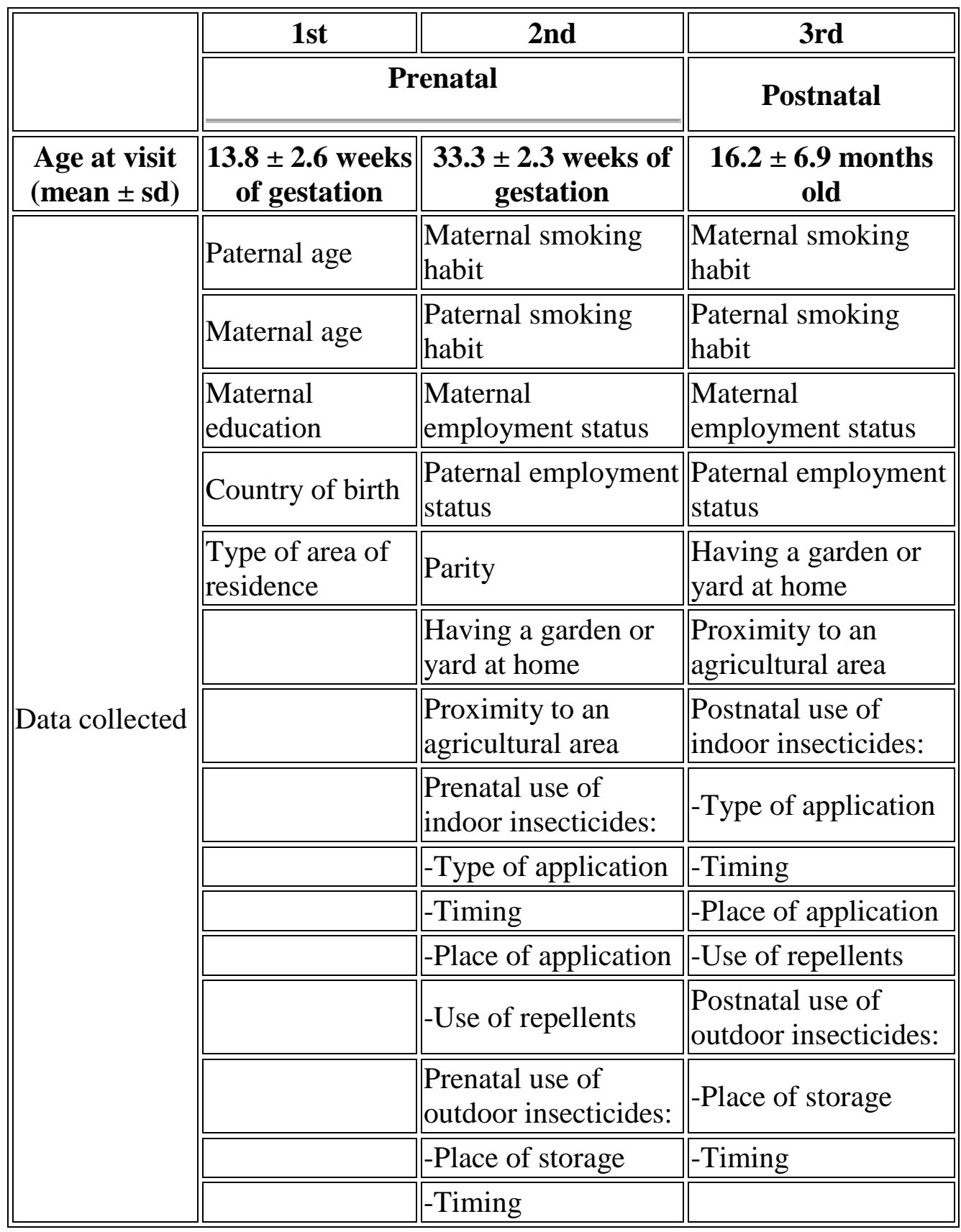


Llop, S., Casas, L., Santa Marina, L., Estarlich, M., Fernández-Somoano, A., Esplugues, A., Jimenez, A., Zock, J.P., Tardón, A., Marco, A., Ballester, F. Prenatal and postnatal residential usage of insecticides in a multicenter birth cohort in Spain. Science of the Total Environment: 7 2013, 445-446, 273-280

Table 2.

Socio-demographic and lifestyle factors of pregnant women in INMA cohort, 2003-2008, Spain.

\begin{tabular}{|c|c|c|c|}
\hline & & \begin{tabular}{|c}
$\begin{array}{c}\text { Original } \\
\text { cohort }(\mathrm{n}= \\
2644) \\
\mathrm{n}(\%)\end{array}$ \\
\end{tabular} & $\begin{array}{c}\text { Pregnant women } \\
\text { participating in this } \\
\text { study }(\mathrm{n}=2456) \\
n(\%)\end{array}$ \\
\hline \multirow{4}{*}{ Region } & Gipuzkoa & $638(24)$ & $601(25)$ \\
\hline & Sabadell & $657(25)$ & $613(25)$ \\
\hline & Asturias & $494(19)$ & $456(19)$ \\
\hline & Valencia & $855(32)$ & $786(32)$ \\
\hline \multirow{3}{*}{ Social class } & $\mathrm{I}$ & $811(31)$ & $771(31)$ \\
\hline & II & $645(25)$ & $623(25)$ \\
\hline & III & $1150(44)$ & $1061(43)$ \\
\hline \multirow{3}{*}{ Parity } & 0 & $1464(56)$ & $1388(57)$ \\
\hline & 1 & $958(37)$ & $898(37)$ \\
\hline & $\geq 2$ & $181(7)$ & $168(7)$ \\
\hline \multirow{2}{*}{$\begin{array}{l}\text { Maternal } \\
\text { employment status } \\
\text { during pregnancy }\end{array}$} & Unemployed & $436(17)$ & $398(16)$ \\
\hline & Employed & || $2171(83)$ & $2058(84)$ \\
\hline \multirow{2}{*}{\begin{tabular}{|l} 
Paternal \\
employment status \\
during pregnancy \\
\end{tabular}} & Unemployed & $40(2)$ & $36(2)$ \\
\hline & Employed & |2550 (99) & $2406(99)$ \\
\hline \multirow{2}{*}{$\begin{array}{l}\text { Paternal job related } \\
\text { to the agricultural } \\
\text { sector }\end{array}$} & No & $2524(99)$ & 2378 (99) \\
\hline & Yes & 21 (1) & $20(1)$ \\
\hline \multirow{2}{*}{$\begin{array}{l}\text { Smoking during } \\
\text { pregnancy }\end{array}$} & No & $2037(83)$ & $2034(83)$ \\
\hline & Yes & 418 (17) & $418(17)$ \\
\hline \multirow{2}{*}{$\begin{array}{l}\text { Paternal smoking } \\
\text { during pregnancy }\end{array}$} & No & $1498(61)$ & $1495(61)$ \\
\hline & Yes & $957(39)$ & $957(39)$ \\
\hline \multirow{2}{*}{$\begin{array}{l}\begin{array}{l}\text { Postnatal maternal } \\
\text { smoking habit }\end{array} \\
\end{array}$} & No & $1601(74)$ & $1574(74)$ \\
\hline & Yes & $567(26)$ & $556(26)$ \\
\hline \multirow{2}{*}{$\begin{array}{l}\text { Postnatal paternal } \\
\text { smoking habit }\end{array}$} & No & $1326(61)$ & $1301(61)$ \\
\hline & Yes & $834(39)$ & $821(39)$ \\
\hline \multirow{2}{*}{ Country of birth } & Other & $220(9)$ & $201(8)$ \\
\hline & Spain & $2378(92)$ & $2248(92)$ \\
\hline Type of area & $\begin{array}{l}\text { Rural/semi- } \\
\text { urban }\end{array}$ & $476(18)$ & $460(19)$ \\
\hline
\end{tabular}


Llop, S., Casas, L., Santa Marina, L., Estarlich, M., Fernández-Somoano, A., Esplugues, A., Jimenez, A., Zock, J.P., Tardón, A., Marco, A., Ballester, F. Prenatal and postnatal residential usage of insecticides in a multicenter birth cohort in Spain. Science of the Total Environment: 7 2013, 445-446, 273-280

\begin{tabular}{|c|c|c|c|}
\hline & & 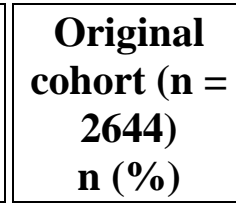 & $\begin{array}{c}\text { Pregnant women } \\
\text { participating in this } \\
\text { study }(\mathrm{n}=2456) \\
n(\%)\end{array}$ \\
\hline & Urban & $2157(82)$ & $1995(81)$ \\
\hline \multirow{3}{*}{$\begin{array}{l}\text { Maternal } \\
\text { educational level }\end{array}$} & $\begin{array}{l}\text { Primary or } \\
\text { without } \\
\text { education }\end{array}$ & $651(25)$ & 597 (24) \\
\hline & Secondary & $1078(41)$ & $1018(41)$ \\
\hline & University & $872(34)$ & 837 (34) \\
\hline \multirow{2}{*}{$\begin{array}{l}\text { Garden or backyard } \\
\text { with plants at home }\end{array}$} & No & $1906(78)$ & $1906(78)$ \\
\hline & Yes & $550(22)$ & 550 (22) \\
\hline \multirow{2}{*}{$\begin{array}{l}\text { Is your home near } \\
\text { an agricultural area? }\end{array}$} & No & $1737(71)$ & $1737(71)$ \\
\hline & Yes & $718(29)$ & $718(29)$ \\
\hline \multirow{4}{*}{$\begin{array}{l}\text { Distance from the } \\
\text { home to an } \\
\text { agricultural area }\end{array}$} & Far $(>200 \mathrm{~m})$ & $328(46)$ & $328(46)$ \\
\hline & $\begin{array}{l}\text { Not very far } \\
(100-200 \mathrm{~m})\end{array}$ & 134 (19) & 134 (19) \\
\hline & $\begin{array}{l}\text { Nearby (50-100 } \\
\text { m) }\end{array}$ & $93(13)$ & 93 (13) \\
\hline & $\begin{array}{l}\text { Very nearby }(< \\
50 \mathrm{~m})\end{array}$ & |161 (23) & $161(23)$ \\
\hline & & Mean (sd) & Mean (sd) \\
\hline Maternal age & & $30.6(4.4)$ & $30.6(4.3)$ \\
\hline Paternal age & & $32.7(5.1)$ & $32.8(5.0)$ \\
\hline
\end{tabular}

Total \% does not always add up to $100 \%$ due to rounding.

Social class: class I included managerial jobs, senior technical staff, and commercial managers; class II included skilled non-manual workers; and class III, manual workers. 
Llop, S., Casas, L., Santa Marina, L., Estarlich, M., Fernández-Somoano, A., Esplugues, A., Jimenez, A., Zock, J.P., Tardón, A., Marco, A., Ballester, F. Prenatal and postnatal residential usage of insecticides in a multicenter birth cohort in Spain. Science of the Total Environment: 2013, 445-446, 273-280

Table 3

Insecticide use and storage patterns among pregnant women of INMA cohort 2003-2008 ( $\mathrm{N}$ total =2 456), Spain.

\begin{tabular}{|c|c|c|}
\hline & $\begin{array}{l}\text { Prenatal insecticide } \\
\text { usage and storage }\end{array}$ & $\begin{array}{c}\text { Early postnatal } \\
\text { insecticide usage and } \\
\text { storage }\end{array}$ \\
\hline Indoor use insecticides & $\mathrm{N}(\%)$ & $\mathrm{N}$ \\
\hline Any use & $1328(54)$ & $1046(45)$ \\
\hline Combination of $\geq 2$ types of products & $366(15)$ & $260(11)$ \\
\hline \multicolumn{3}{|l|}{ Use in the pregnant woman's bedroom/children's bedroom } \\
\hline Any use & $1093(45)$ & $764(33)$ \\
\hline Whole year & $60(5)$ & $32(4)$ \\
\hline Seasonal & $815(75)$ & $592(77)$ \\
\hline Occasional & $218(20)$ & $140(18)$ \\
\hline Insecticide sprays & $575(53)$ & $202(26)$ \\
\hline Plug-in devices & $681(62)$ & $575(75)$ \\
\hline Other types & $26(2)$ & $77(10)$ \\
\hline \multicolumn{3}{|l|}{ Use elsewhere in the house } \\
\hline Any use & $1142(47)$ & $896(39)$ \\
\hline Whole year & $76(7)$ & $45(5)$ \\
\hline Seasonal & $768(67)$ & $632(70)$ \\
\hline Occasional & $298(26)$ & $219(24)$ \\
\hline Insecticide sprays & $792(69)$ & $465(52)$ \\
\hline Plug-in devices & $524(46)$ & $519(58)$ \\
\hline Other types & $63(5)$ & $93(10)$ \\
\hline Outdoor use insecticides or other pesticides & $\mathrm{N}(\%)$ & $\mathrm{N}(\%)$ \\
\hline Any use & $235(10)$ & $194(8)$ \\
\hline Every month & $22(9)$ & $19(10)$ \\
\hline Every 2-3 months & $32(14)$ & $21(11)$ \\
\hline 3 times/year & $47(20)$ & $42(22)$ \\
\hline Occasionally & $132(57)$ & $109(57)$ \\
\hline Always applied by the pregnant woman & $38(16)$ & \\
\hline Sometimes applied by the pregnant woman & $31(13)$ & \\
\hline Stored in the garage & $87(47)$ & $66(43)$ \\
\hline Stored outdoors & $56(30)$ & $51(33)$ \\
\hline Stored elsewhere & $44(24)$ & $37(24)$ \\
\hline
\end{tabular}

Percentages in bold have been calculated from the total sample size. 
Llop, S., Casas, L., Santa Marina, L., Estarlich, M., Fernández-Somoano, A., Esplugues, A., Jimenez, A., Zock, J.P., Tardón, A., Marco, A., Ballester, F. Prenatal and postnatal residential usage of insecticides in a multicenter birth cohort in Spain. Science of the Total Environment: 7 2013, 445-446, 273-280

Table 4.

Multivariable logistic regression models between use of indoor insecticides and use of insecticide sprays during pregnancy and socio-demographic and lifestyle characteristics of pregnant women. INMA Cohort, Spain, 20032008.

\begin{tabular}{|c|c|c|c|c|c|c|c|}
\hline & & \multicolumn{3}{|c|}{$\begin{array}{c}\text { Use of indoor } \\
\text { insecticides pseudo } \\
\mathbf{r}^{2}=\mathbf{0 . 0 9 0 0}\end{array}$} & \multicolumn{3}{|c|}{$\begin{array}{c}\text { Use of insecticide } \\
\text { sprays pseudo } r^{2}= \\
0.0650\end{array}$} \\
\hline & & OR & $\begin{array}{c}(95 \% \\
\mathrm{CI}) \\
\end{array}$ & $\begin{array}{c}\text { p- } \\
\text { Value }\end{array}$ & OR & $\begin{array}{c}(95 \% \\
\text { CI })\end{array}$ & $\begin{array}{c}\text { p- } \\
\text { Value }\end{array}$ \\
\hline \multirow{3}{*}{ Social class } & $\mathrm{I}$ & & & & & & \\
\hline & II & & NS & & 1.09 & $\begin{array}{l}(0.77 \\
1.53)\end{array}$ & 0.627 \\
\hline & III & & & & 1.64 & $\begin{array}{l}(1.16 \\
2.31)\end{array}$ & 0.005 \\
\hline \multirow{3}{*}{ Parity } & 0 & & & & & & \\
\hline & 1 & 1.14 & $\begin{array}{l}(0.95 \\
1.37) \\
\end{array}$ & 0.144 & 0.73 & $\begin{array}{l}0.57 \\
0.94)\end{array}$ & 0.014 \\
\hline & $\geq 2$ & 1.55 & $\begin{array}{l}(1.08 \\
2.21)\end{array}$ & 0.016 & 0.69 & $\left(\begin{array}{l}0.44 \\
1.08)\end{array}\right.$ & 0.103 \\
\hline \multirow{2}{*}{$\begin{array}{l}\text { Country of } \\
\text { birth }\end{array}$} & Other & & & & & & \\
\hline & Spain & 1.78 & $\begin{array}{l}(1.31 \\
2.41)\end{array}$ & $<0.001$ & 0.55 & \begin{tabular}{|l}
$(0.33$ \\
$0.90)$
\end{tabular} & 0.018 \\
\hline \multirow{2}{*}{ Type of area } & $\begin{array}{l}\text { Rural/semi- } \\
\text { urban }\end{array}$ & & & & & & \\
\hline & Urban & & NS & & 0.54 & \begin{tabular}{|l}
0.36 \\
$0.81)$
\end{tabular} & 0.003 \\
\hline \multirow{3}{*}{$\begin{array}{l}\text { Maternal } \\
\text { educational } \\
\text { level }\end{array}$} & $\begin{array}{l}\text { Primary or } \\
\text { without } \\
\text { education }\end{array}$ & & & & & & \\
\hline & Secondary & 0.90 & $\begin{array}{l}0.72 \\
1.12)\end{array}$ & 0.328 & 0.70 & $\begin{array}{l}0.52 \\
0.95) \\
\end{array}$ & 0.022 \\
\hline & University & 0.67 & $\begin{array}{l}0.53 \\
0.85)\end{array}$ & 0.001 & 0.79 & $\left(\begin{array}{l}0.53 \\
1.16)\end{array}\right.$ & 0.222 \\
\hline \multirow{2}{*}{$\begin{array}{l}\text { Garden or } \\
\text { backyard with } \\
\text { plants at home }\end{array}$} & No & & & & & & \\
\hline & Yes & 2.06 & $\begin{array}{l}(1.66 \\
2.56)\end{array}$ & $<0.001$ & $\mid 1.69$ & $\begin{array}{l}(1.29 \\
2.22)\end{array}$ & $<0.001$ \\
\hline \multirow{2}{*}{$\begin{array}{l}\text { Is your home } \\
\text { near an } \\
\text { agricultural }\end{array}$} & No & & & & & & \\
\hline & Yes & 1.39 & $\begin{array}{l}(1.14 \\
1.70)\end{array}$ & 0.001 & 1.52 & $\begin{array}{l}(1.17 \\
1.99)\end{array}$ & 0.002 \\
\hline
\end{tabular}


Llop, S., Casas, L., Santa Marina, L., Estarlich, M., Fernández-Somoano, A., Esplugues, A., Jimenez, A., Zock, J.P., Tardón, A., Marco, A., Ballester, F. Prenatal and postnatal residential usage of insecticides in a multicenter birth cohort in Spain. Science of the Total Environment: 7 2013, 445-446, 273-280 niver

\begin{tabular}{|c|c|c|c|c|c|c|c|}
\hline & & \multicolumn{3}{|c|}{$\begin{array}{c}\text { Use of indoor } \\
\text { insecticides pseudo } \\
\mathbf{r}^{2}=\mathbf{0 . 0 9 0 0}\end{array}$} & \multicolumn{3}{|c|}{$\begin{array}{l}\text { Use of insecticide } \\
\text { sprays pseudo } r^{2}= \\
0.0650\end{array}$} \\
\hline & & OR & $\begin{array}{c}(95 \% \\
\text { CI }) \\
\end{array}$ & $\begin{array}{c}\text { p- } \\
\text { Value }\end{array}$ & OR & $\begin{array}{c}(95 \% \\
\text { CI) } \\
\end{array}$ & \begin{tabular}{|c|} 
p- \\
Value
\end{tabular} \\
\hline \multicolumn{8}{|l|}{ area? } \\
\hline \multirow{4}{*}{ Region } & Gipuzkoa & & & & & & \\
\hline & Sabadell & 4.49 & $\begin{array}{l}(3.48 \\
5.80)\end{array}$ & $<0.001$ & 1.55 & $\begin{array}{l}(1.00 \\
2.39)\end{array}$ & 0.049 \\
\hline & Asturias & 2.59 & $\begin{array}{l}(1.99 \\
3.37)\end{array}$ & $<0.001$ & 1.17 & \begin{tabular}{|l}
$(0.75$ \\
$1.83)$
\end{tabular} & 0.498 \\
\hline & Valencia & 3.46 & \begin{tabular}{|l|}
$(2.72$ \\
$4.40)$
\end{tabular} & $<0.001$ & 2.39 & \begin{tabular}{|l}
$(1.58$ \\
$3.61)$
\end{tabular} & $<0.001$ \\
\hline
\end{tabular}

OR: Odds ratio.

95\% CI: 95\% Confidence intervals.

NS: Not statistically significant.

Reference categories: social class I, parity $=0$, not Spanish, living in a rural/semiurban zone, primary studies or without education, not having a garden or backyard with plants, not living near an agricultural area, living in the Gipuzkoa region.

Table 5.

Distribution of women according to their prenatal and postnatal use of residential insecticides.

\begin{tabular}{|c|c|c|c|c|c|}
\hline & \multicolumn{3}{|c|}{$\begin{array}{c}\text { Women who used } \\
\text { residential insecticides } \\
\text { prenatally }\end{array}$} & \multirow{2}{*}{$\begin{array}{l}\text { Spearman } \\
\text { correlation } \\
\text { coefficient }\end{array}$} \\
\hline & & Yes & No & Total & \\
\hline \multirow{3}{*}{$\begin{array}{l}\text { Women who used } \\
\text { residential insecticides } \\
\text { postnatally }\end{array}$} & Yes & \begin{tabular}{|l|}
788 \\
$(34 \%)$ \\
\end{tabular} & \begin{tabular}{|l}
258 \\
$(11 \%)$
\end{tabular} & 1046 & \multirow{3}{*}{$0.397(\mathrm{p}<0.001)$} \\
\hline & No & \begin{tabular}{|l}
450 \\
$(20 \%)$
\end{tabular} & $\begin{array}{l}812 \\
(35 \%)\end{array}$ & $\mid 1262$ & \\
\hline & Total & 1238 & 1070 & 2308 & \\
\hline
\end{tabular}


Llop, S., Casas, L., Santa Marina, L., Estarlich, M., Fernández-Somoano, A., Esplugues, A., Jimenez, A., Zock, J.P., Tardón, A., Marco, A., Ballester, F. Prenatal and postnatal residential usage of insecticides in a multicenter birth cohort in Spain. Science of the Total Environment: 7 2013, 445-446, 273-280

Table 6.

Multivariable logistic regression models between a change in habit in residential insecticide use indoors and socio-demographic and lifestyle characteristics of pregnant women. INMA Cohort, Spain, 2003-2008 $(n=2$ 308).

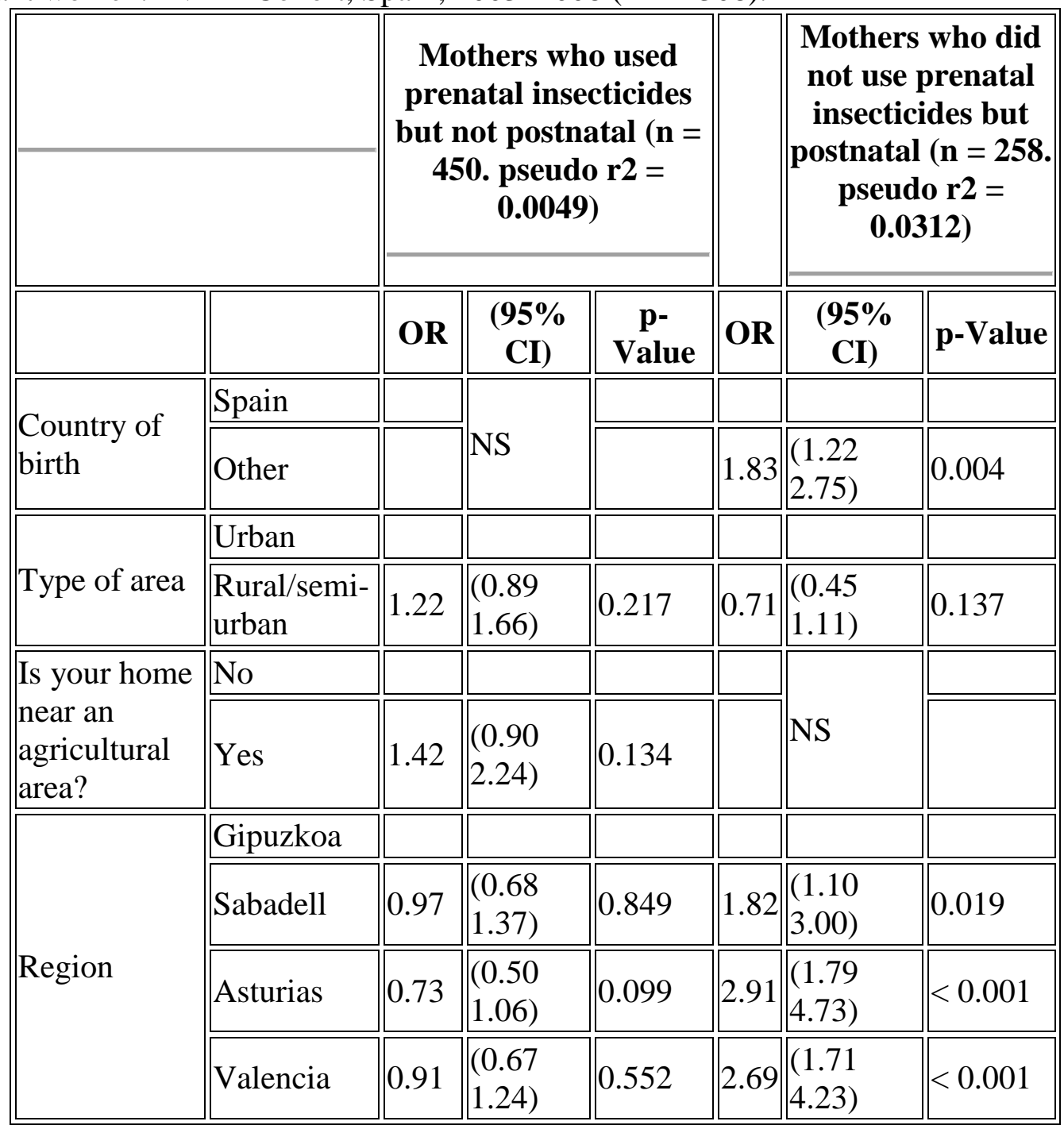

The reference population in regression logistic models was those women who did not change their habit of using insecticide.

OR: Odds ratio.

95\% CI: 95\% Confidence intervals.

NS: not statistically significant.

Reference categories: Spanish mothers, living in an urban area, not living near an agricultural area, and living in Gipuzkoa region. 